\title{
Blockchain Technology and Real Estate - a cluster analysis of applications in global markets in the year 2021
}

\author{
Philipp Schmidt ${ }^{1 *}$, David Elferich ${ }^{2 * *}$ \\ ${ }^{1}$ University of applied Science - International School of Management (ISM), Otto-Hahn-Straße 19, \\ 44227 Dortmund \\ ${ }^{2}$ University of Kosice, Faculty of Economics, Letná 9, 04200 Košice / Berlin Institute of Finance, \\ Innovation and Digitalization e. V., Badensche Straße 52, 10825 Berlin
}

\begin{abstract}
Research background: Since the announcement by entrepreneur Elon Musk in the year 2021 about the inclusion of Bitcoin on the balance sheet of his automotive company Tesla, the economic significance of cryptocurrencies for the financial industry is taking on progressive importance. In addition to the financial economic consideration of cryptocurrencies, the underlying blockchain technology is undergoing a disruptive growth across industries - e.g. from automotive to real estate. Accordingly, in the report 'Deep Shift Technology Tipping Points and Societal Impact', the World Economic Forum predicted a far-reaching significance of the blockchain technology as early as 2015 , and in 2020 , the Global Future Council published a finding that the crypto market has reached a point of inevitability.

Purpose of the article: The aim of this paper is to examine the degree of integration of the blockchain technology within the framework of a current market investigation using the real estate industry as an example. The leading application areas of the blockchain technology in the real estate industry will be presented.

Methods: The market investigation of this paper is based, among other things, on a cluster analysis that examines a regional differentiation of the application areas on a global level.

Findings \& Value added: In this context, the market research indicates that the blockchain technology can be applied significantly in the real estate industry and that the Global Future Council finding can be replicated in many areas.
\end{abstract}

Keywords: Blockchain Technology, Real Estate, Applications

\footnotetext{
Corresponding author:

philippanton.schmidt@gmail.com

** Corresponding author: david.elferich@gmail.com
} 
JEL Classification: R30, D53, O32, F30, E22

\section{Introduction}

Since the financial banking crisis in 2008, a year of historic fiscal turmoil, there has been a wave of disruption across industries through regulatory measures. This year has seen the release of a breakthrough technological invention that remained in the shadows of global digitization efforts for many years, until its global disruption effect emerged so significantly in 2020/2021 that entire sectors of the economy are anticipating an existential transformation. This refers to the publication of the white paper named "Bitcoin: A Peer-to-Peer E-cash System" (Nakamoto, 2008), the birth of a cryptocurrency that, as a pioneering position, subsequently led to a multitude of other cryptocurrencies with considerable growth progress (Coinmarketcap, 2021). A finding that was already published by the World Economic Forum in 2015 in the annual report 'Deep Shift Technology Tipping Points and Societal Impact' (World Economic Forum, 2015), and renewed in significance in 2020 as part of the publication series 'Great Resets' (World Economic Forum, 2021). Accordingly, it was stated that "Cryptocurrencies have reached a point of inevitability" (World Economic Forum, 2020). A statement of societal and institutional significance that has been accompanied by significant societal awareness growth, particularly since the global impact of the COVID-19 pandemic (Demir et al., 2020). Thus, two dominant players have essentially shaped market events in recent years, after which Bitcoin had a market capitalization of approximately $\$ 1.179$ trillion at its all-time high on April 14, 2021. If the market capitalization of Ethereum, the second largest cryptocurrency, is also added up, the result was an overall market capitalization of more than 80 percent of all cryptocurrencies (Imöhl and Ivanov, 2021). However, when considering the distribution of market capitalization, as of 05.09.2021, a total of 11,636 different cryptocurrencies must be taken into account, which are expected to play an increasingly important role in the future (Mashayekhi, 2021). In this regard, the regulatory differentiation of the multitude of cryptocurrencies is a particularly significant challenge for international boards, after which the U.S. Securities and Exchange Commission (SEC) has issued a definition that requires a case-by-case decision (Trautman and Dormann, 2018). The core of any classification attempt is based on the interpretation of the individual intended use and the underlying industry and technology use (Inci and Lagasse, 2019). Following this approach, the informational basis of the technology is presented below first, followed by an introduction of arguably one of the most forward-looking industry sectors for the underlying technology.

\section{What is a blockchain?}

What exactly is the term 'blockchain technology'? A blockchain is a secure, digitized, decentralized and publicly viewable data storage that allows transactions to be recorded via an immutable storage history (Dudgeon and Malna, 2018). In this process, the dataset grows continuously as completed transactions are incrementally added to a "chain" in the form of combined groups called "blocks." By chaining these "blocks" together, a chronological, immutable storage history of the so-called "blockchain" is created. In this context, the security of a blockchain is essentially determined by a characterizing "distributed" data network, which is presented below in contrast to the essential data network structures. 

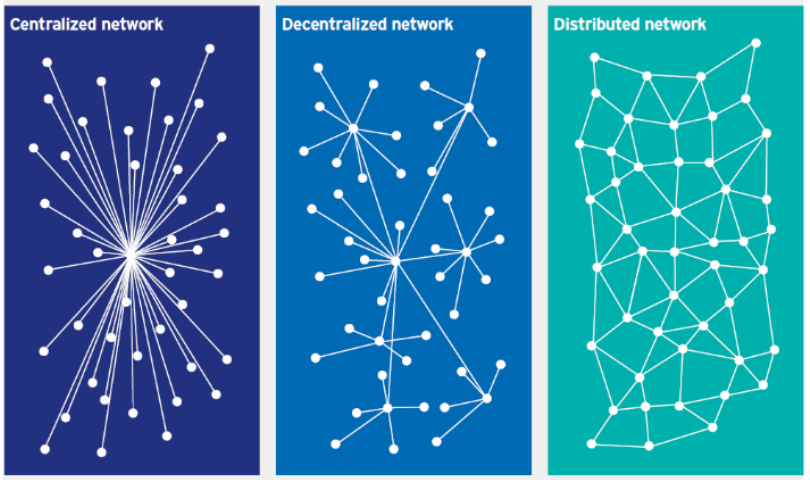

Figure 1. Blockchain as a distributed network.

Source: Dowsett \& Wied (n.d.)

The significance of blockchain technologies lies in the distributed storage of data, which is stored in the form of a ledger within the framework of an unchangeable protocol of all transactions. Thus, every transaction and the associated information or even a linked asset can be located and assigned to an entity at any time. Until now, financial and government institutions, for example, have had the prerogative to manage databases and share them publicly only selectively with external parties (Symbiont, 2016). Using the example of a "centralized" as well as a "distributed" data network, this has historically led to information asymmetries and limited information legitimacy. A "distributed" data network, on the other hand, takes advantage of a "shared" network that allows an identical copy of the ledger to be available to all actors at all times (Hancock and Vaizey, 2016). This eliminates the need for a central control authority, as each copy of the ledger is automatically synchronized when a transaction is immutably added to the data network "chain" (Oerle and Lemmens, 2016; Scardovi, 2016). This allows for a tamper-proof and easily accessible network architecture, which in the case of a permission-free "blockchain" allows unrestricted access for any participant (Biondi et al., 2016; Luijtgaarden, 2016).

\section{Blockchain Technology and Real Estate}

In particular for the transaction-intensive areas of the economy, such as the globalized financial markets and commodity management processes, the "blockchain technology" has a significant disruption effect. Here, the "blockchain technology" stores a transaction to be carried out, as previously described, within the framework of an unchangeable data network and enables, through so-called "smart contracts", the information associated with the transaction or even a linked asset. The integration of "smart contracts" equals out the currently still existing natural limits for information and goods transactions, which show an increased illiquidity or legal trade restrictions, through the innovative transaction process. In doing so, completely disruptive economic growth markets are created for all sectors of the economy, such as the transaction-intensive real estate industry, as previously possible limiting information legitimation processes are removed. Blockchain technology makes it possible to create a "digital twin" of any imaginable asset through so-called "tokenization," the digitization of a transactional asset (Burke et al., 2019). This will allow assets, such as real estate, which currently still have a limited transaction radius due to legal and fiscal constraints, to become liquid, free, and multivariable tradable assets. The following globalized transaction process is intended to exemplify the extensive impact of blockchain technology. 


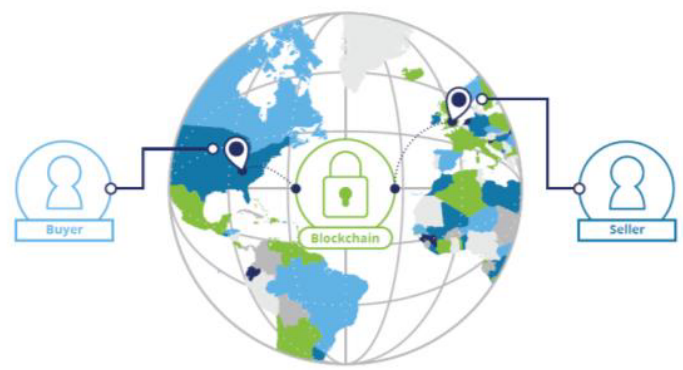

Figure 1. Blockchain technolgie and Real Estate - tokenization of assets.

Source: Deloitte (2017)

For example, in its report "Deep Shift Technology Tipping Points and Societal Impact," the World Economic Forum predicts that an estimated 10 percent of global gross domestic product (GDP) will be traded via blockchain applications by 2027 (World Economic Forum, 2015). Taking the real estate industry as an example, blockchain technology has already integrated wide-ranging applications. For example, the leading crowdfunding platform for real estate financing, Exporo, has launched a Blockchain-based financing foundation for real estate. The use of blockchain technology creates a "digital twin" of a property, enabling the proportional allocation of ownership shares in a property to be reduced to a fraction of the shareholding that would otherwise be required. This allows investors to make diversified investments with a minimal investment volume. At the same time, this process opens up access to otherwise inaccessible forms of investment to a large number of investors (Exporo, 2020). The following cluster analysis of the application areas of blockchain technology in the real estate industry also shows a wide-ranging industry report, which is published as the "FIBREE Industry Report" as one of the essential annual technical papers and represents a global overview of the latest development fields (Fibree, 2021). A differentiation of the application areas must be taken into account here, according to which the real estate industry is to be differentiated between the individual players (investors, owners, users/tenants and developers/property developers) and thus corresponding development fields are also to be segregated, as the following figure shows.

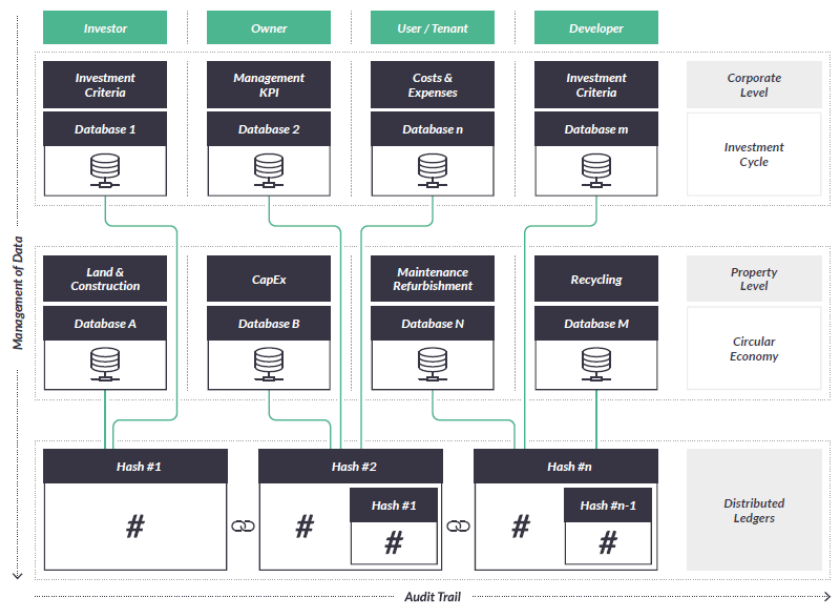

Figure 3. Real Estate and blockchain-based innovation fields.

Source: Fibree (2021) 
For further cluster analysis, the U.S. market is defined below as the region of analysis, so that a regional allocation of the evaluation results can be recorded. Accordingly, the main application areas of blockchain technology are based on Ethereum, Hyperledger and Bitcoin, which were also presented due to the aforementioned pioneering role based on market capitalization (Fibree, 2021). Thus, the 108 application areas identified in 2021 amount to the following sectoral industries, as shown in the figure below.

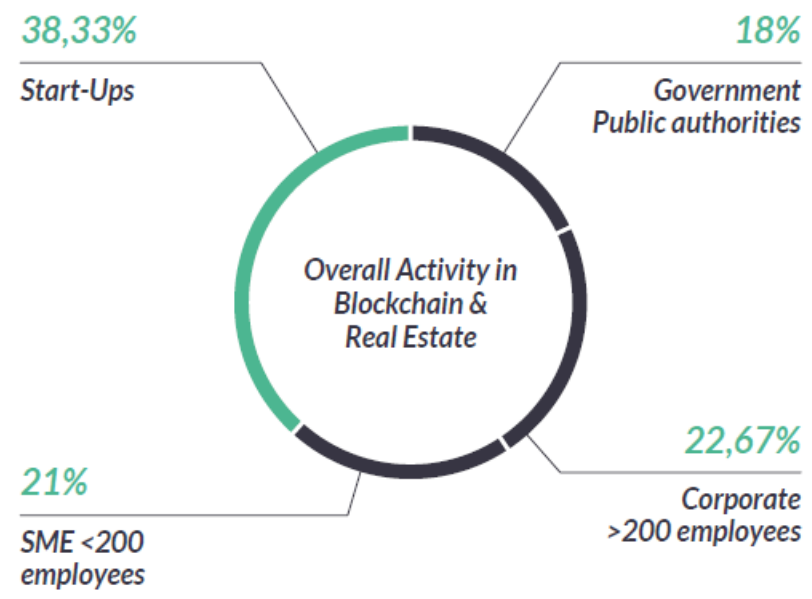

Figure 4. Cluster analyse - Blockchain user levels in US Real Estate markets.

Source: Fibree (2021)

It should be noted that start-ups are the growth drivers of blockchain applications. In second place, SME companies with less than 200 employees, companies with more than 200 employees and government entities are equally weighted (Fibree, 2021). It should be noted that in the year-on-year comparison, there is a significant change in application areas, according to which blockchain-based investment and financial applications have ceded market share to transactional and hedging applications.

In view of the previously listed research results from the "FIBREE Industry Report", a further cluster analysis is set up below. Here, an exploratory evaluation of the existing global application areas of Blockchain technology in the real estate industry is presented based on the tokens listed on the platform CryptoSlate (CryptoSlate, 2021). 


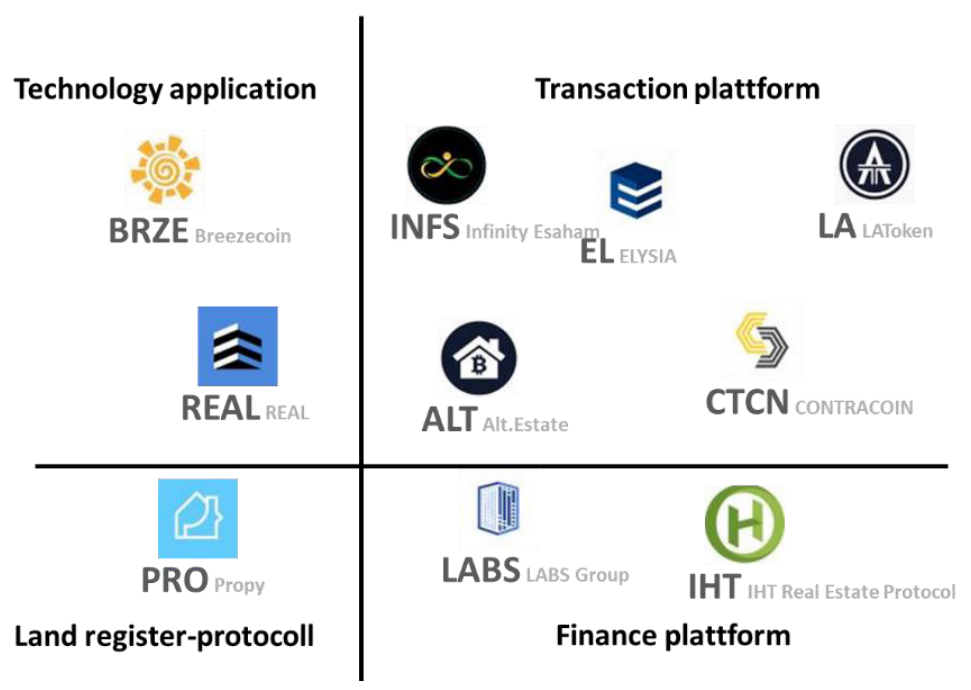

Figure 5. Cluster analyse - Real Estate Tokens - Blockchain Technology.

Source: own research

The cluster analysis clearly shows that transaction platforms represent the main application area of Blockchain applications in the real estate industry measured by the registered tokens. On the other hand, however, the token Propy is noted as the single application in the field of Blockchain supported land registry application. The application areas of technology applications and financing platforms are equally distributed with two application areas.

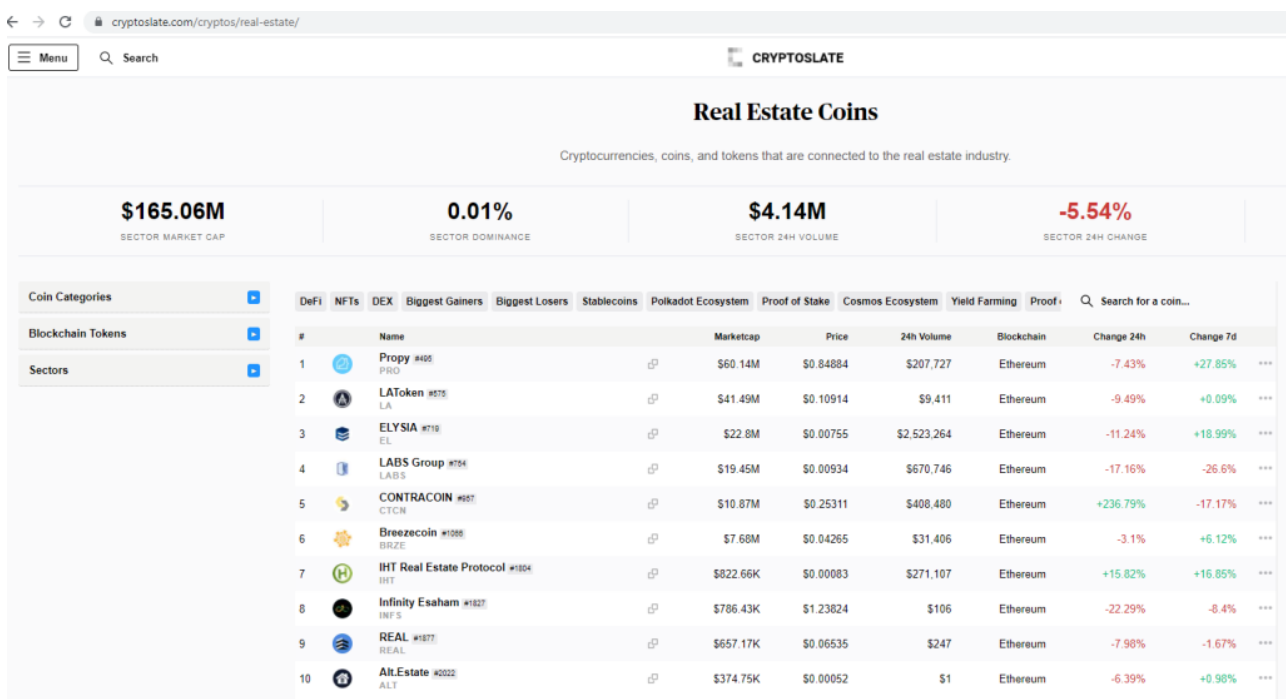

Figure 6. Overview Top 10 Real Estate Tokens by Market Capitalization

Source: Cryptoslate (2021)

In addition, it is important to consider that the market participants have different market capitalization levels, according to which the first-placed company with approx. 6.0 million US dollars, Propy, differs significantly from the tenth-placed company with approx. 0.4 million US dollars, Alt.Estate. 
All in all, it can be concluded that the areas of application on a global evaluation perspective are mainly in the areas of transaction and financing platforms, as also shown in the following evaluation.
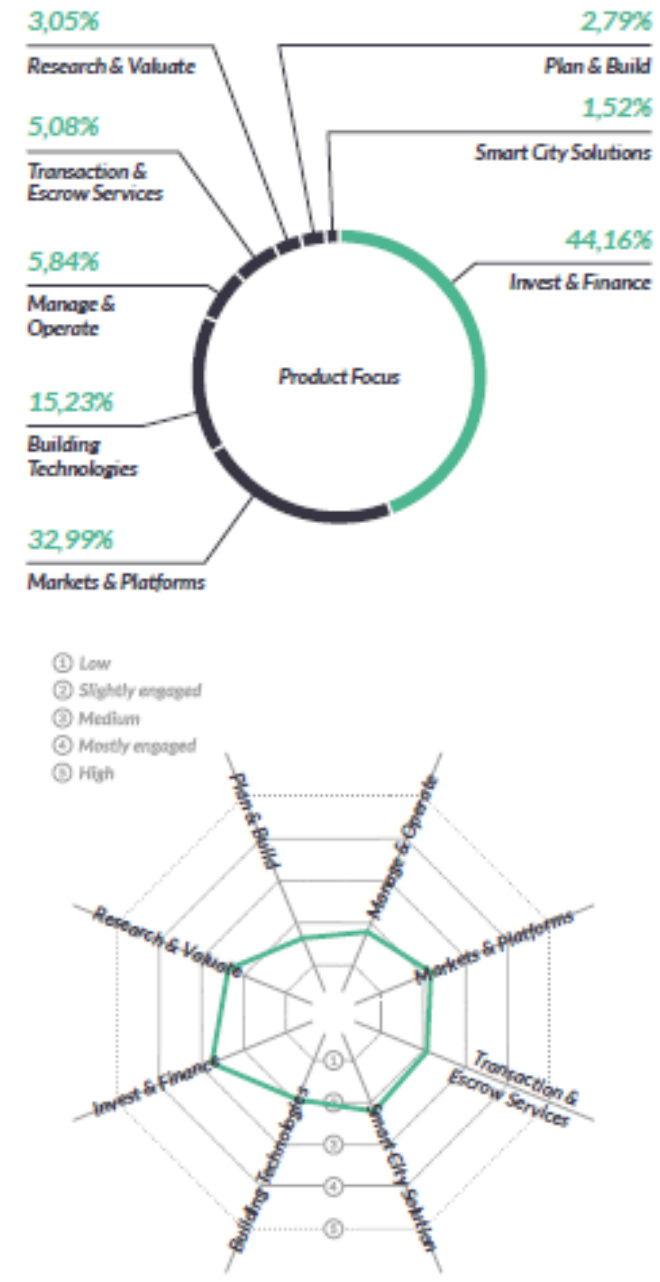

Figure 7. Cluster analyse - Real Estate Applications - Blockchain Technology

Source: Fibree (2021)

According to this, the "FIBREE Industry Report" shows that market platforms for digital commerce in particular also dominate the application areas globally with approx. 32 percent and, in addition, financing platforms together with market platforms already take up more than approx. 76 percent of all registered application areas of blockchain technology in the real estate industry.

\section{Conclusion}

In conclusion, the increase in the significance of blockchain technology for the real estate industry is essential due to an industry-wide development of digital trading and financing platforms and is subject to the disruptive technology approaches of blockchain (Fibree, 
2021). The implementation areas can already be determined here, e.g. the blockchain integration of the leading crowdfunding platform Exporo (Exporo, 2020), according to which the traditionally regulated market structures of the real estate industry are being changed and, due to the "distributed" and publicly visible data structure of blockchain technology, represents one of the central decision-making factors for further development of the real estate industry. In this regard, the "FIBREE Industry Report" points out that "we are at the beginning of a new era in real estate where in the future properties will be judged not only by their brick-and-mortar physical impact but also by their impact on climate and society" (Fibree, 2021). The need for a land registry based on blockchain technology can be defined as a major and essential milestone. This would be necessary in order to be able to clearly assign ownership, whereby the ability to divide the property into small-value tokens represents a challenge here. New rules need to be developed as to who is the "substantial" owner of a property and can thus determine what may be done with the property and how. An example is provided by the capital markets with shares, where it is clearly regulated by law which majorities can decide what.

\section{References}

1. Biondi, D., Hetterscheidt,T., \& Obermeier, B. (2016). Blockchain in the financial services industry. Blockchanilab. https://blockchainlab.com/pdf/4AA6-5864ENW.pdf

2. CoinMarketCap. (2021, August 20). Bitcoin. CoinMarketCap https://coinmarketcap.com/currencies/bitcoin/.

3. CryptoSlate. (2021, September 19). Real Estate Coins. Cryptoslate. https:/cryptoslate.com/cryptos/real-estate/

4. Deloitte, Laurent, P., Chollet T., Burke, M., Seers, T. (2019). The tokenization of assets is disrupting the financial industry. Are you ready? https://www2.deloitte.com/content/dam/Deloitte/lu/Documents /financial-services/lutokenization-of-assets-disrupting-financial-industry.pdf

5. Demir, Bilgin, Karabulut, Doker. (2020, July 29). The relationship between cryptocurrencies and COVID-19
https:/link springer.com/article/10.1007/s40822-020-00154-1

6. Dudgeon, N., Malna, G. (2018). Distributed Ledger Technology: From Blockchain to ICOs. Banking \& Financial Services Policy Report, 37(2).

7. Exporo. (2020, June 23). Die Blockchain-Technologie in der Immobilienwirtschaft. Expro. https://exporo.de/blog/die-blockchain-technologie-in-der-immobilienwirtschaft/

8. Fibree. (2021, June 24). Industry Report Blockchain Real Estate 2021. Fibree. https://fibree.org/industry-report/

9. Hancock, M., Vaizey, E. (2016, January 18). Distributed Ledger Technology: beyond block chain. Assets Publishing Service. https://assets.publishing.service.gov.uk/government/uploads/ system/uploads/attachment_data/file/492972/gs-16-1-distributed-ledger-technology.pdf

10. Imöhl, Ivanov. (2021, September 13). Das sind die zehn größten Kryptowährungen nach Marktkapitalisierung. Handelsblatt. https://www.handelsblatt.com/finanzen/bitcoin- 
ethereum-cardano-und-co-das-sind-die-zehn-groessten-kryptowaehrungen-nachmarktkapitalisierung/27416084.html

11. Inci, A.C., Lagasse, R. (2019). Cryptocurrencies: applications and investment opportunities. Journal of Capital Markets Studies, 10.1108/JCMS-05-2019-0032, 3(2), 98-112

12. Mashayekhi. (2021, August 13). What are stablecoins? Your guide to the fast-rising alternative to Bitcoin and Ethereum. Fortune. https://fortune.com/2021/08/13/what-arestablecoins-crypto-bitcoin-ethereum-dogecoin/.

13. Nakamoto, S. (2008, November 1) Bitcoin: A peer-to-peer electronic cash system. Bitcoin. https://www.bitcoin.de/de/bitcoin-whitepaper-deutsch

14. Scardovi, C., (2016). Restructuring and innovation in banking. Cham: Springer International Publishing. SpringerBriefs in Finance.

15. Symbiont. (2016, January 18). Distributed Ledgers and Centralized Databases. Financial Times. https://www.ft.com/stream/4912f203-bc88-4250-a121-97e106a13af8

16. Trautman, L.J., Dorman, T. (2018). Bitcoin as Asset Class. SSRN Electronic Journal. $10.2139 /$ ssrn. 3218007

17. van Oerle, J., Lemmens, P. (2016). Distributed ledger technology for the financial industry. Robeco The Investment Engineers. https://caia.org/sites/default/files/1.distributed_ledger_for_financial_industry.pdf

18. van de Luijtgaarden, N. (2017). Optimizing the core business processes of financial asset management companies using blockchain technology. Student Undergraduate Research Journal (Vol. 3), 144-147. https://doi.org/10.25609/sure.v3.2548

19. World Economic Forum. (2015, September). Deep shift technology tipping points and societal impact. World Economic Forum. http//www3.weforum.org/docs/wef_gac15_ technological_tipping_points_report_2015.pdf

20. World Economic Forum. (2020, December). Crypto, What is it good for? An overview of cryptocurrency use cases. World Economic Forum. http://www3.weforum.org/docs/wef_crypto currency_uses_cases_2020.pdf

21. World Economic Forum. (2021, January 26). The great reset. World Economic Forum. https://www.weforum.org/great-reset/ 